\title{
A Case Study in User Support for Managing OpenSim based Multi User Learning Environments
}

\author{
Indika Perera, Member IEEE, Alan Miller and Colin Allison, Member IEEE
}

\begin{abstract}
Immersive 3D Multi User Learning Environments (MULE) have shown sufficient success to warrant their consideration as a mainstream educational paradigm. These are based on 3D Multi User Virtual Environment platforms (MUVE), and although they have been used for various innovative educational projects their complex permission systems and large numbers of functions can make their management potentially challenging. It follows that an inadequately managed MULE can be ineffective with respect to intended learning outcomes. The purpose of this research was to determine how management challenges manifest themselves and how to support educators in learning and applying MULE management skills. We utilised the popular OpenSim platform for this study. Firstly, a survey of the need for user support $(\mathrm{N}=43)$ is described. Next, the design and evaluation of a guidance tool using graph topologic visualisation of OpenSim functions is presented $(\mathrm{N}=211)$. The tool is further evaluated in the delivery of a course module. The analysis and user feedback indicated that the tool provides accurate information and helpful support for MULE management. As the final phase of the research, training environments were developed for both basic and advanced OpenSim MULE management. Evaluations of their usability and perceived educational value were carried out with participants $(\mathrm{N}=68)$; the outcomes suggest that training for advanced MULE management is more useful for all users, without requiring more time or effort, regardless of the degree of complexity of the MULE being designed.
\end{abstract}

Index Terms - Virtual Worlds, Immersive 3D learning environments, Immersive Learning Environment Management

\section{INTRODUCTION}

Tmmersive 3D Multi User Virtual Environments (MUVE) are used in a number of different application domains including training, games, entertainment, social networking, advertising, architectural and civil engineering visualisations and education. It is important to note that MUVE platforms were not designed to support educational environments per se (any more than the Web was). However, due to their unique capabilities, they have been of significant research interest to educationalists for some time, and particularly since the advent of the Second Life commercial MUVE service in 2003 [1] which made such environments much more accessible. We refer to a MUVE used specifically for education as a Multi User Learning Environment (MULE). MULEs provide unique features for enhancing learning through immersive and engaging activities for learning complex and advanced concepts. They are particularly appropriate for supporting collaborative learning, experiential learning, and learning through experimentation as a particular form of exploration [7]. For example, Fig. 1 shows a scenario from Network Island [8] [9] where students are experimenting with Internet routing algorithms.

Second Life is a sophisticated client-server system in which users run client-viewer applications and are repre-

- Indika Perera is with the Department of Computer Science and Engineering in the Faculty of Engineering at the University of Moratuwa, Katubedda, Sri Lanka (10400). E-mail: indika@cse.mrt.ac.lk.

- Alan Miller is with the School of Computer Science, University of St Andrews, UK, KY16 9SX. E-mail: alan.miller@st-andrews.ac.uk.

- Colin Allison is with the School of Computer Science, University of St Andrews, UK, KY16 9SX. E-mail: ca@st-andrews.ac.uk.

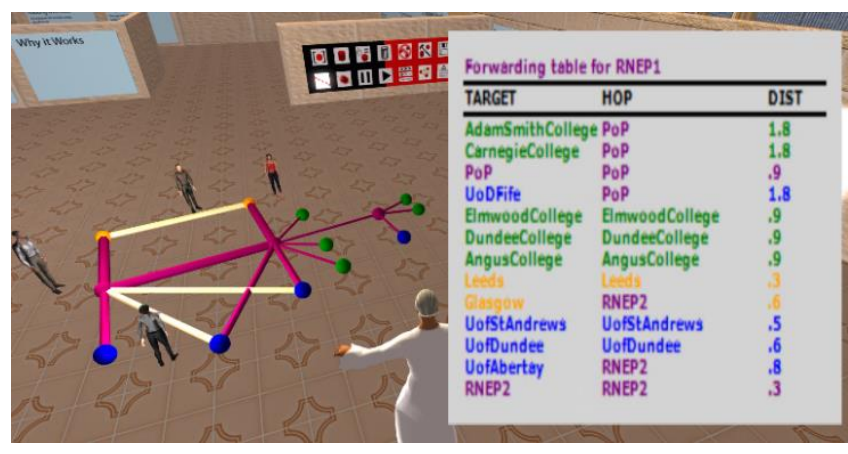

Figure 1: A MULE for Internet Routing. A student has broken a link in and the forwarding table adjusts in accordance with the routing algorithm being studied. Intervening frames (not shown) display and accurate animation of routing protocol control packets being exchanged between nodes.

sented by avatars in a shared real-time environment maintained by a server. Open Simulator [2] (OpenSim) was released as an open source project in 2008. It effectively reverse-engineered the Second Life communication protocols and object models. An OpenSim server therefore provides all the functionality of a Second Life server, and adds significant enhancements. MUVE client-viewer applications that can be used with Second Life, such as Firestorm [3] and the Second Life viewer [4], can also be used with OpenSim. By 2010 many educators, including NASA [5] had moved from Second Life to OpenSim for a variety of reasons [6]. Second Life drawbacks included: financial cost, limited programmability and configurability, limited control over distracting non-educational content, restricted program resource usage, severely constrained backup, copy and sharing of content 
(including one's own), and limited communications with entities outside of the virtual world. Accordingly, we have used OpenSim as our standard MUVE platform since 2010, and the research reported in this paper was carried out in an OpenSim context.

Although MULEs based on OpenSim can be educationally engaging and effective, managing them can be a challenge due to the complexity of configuring OpenSim to meet the needs of a bespoke learning environment [10]. For example, we have calculated that OpenSim has over 200 functions and 350 functional interrelationships that can be relevant to configuring a learning environment - a daunting prospect for any newcomer. Moreover, a lack of systematic management can have a negative impact on intended learning outcomes. For example: project groups may need privacy from each other when carrying out course work whereas the lecturer or demonstrator requires universal access in order to assist or assess; allowing avatars to fly may be inappropriate in certain contexts, whereas guided teleporting to a specific set of learning resources may be required. To address this problem of configuration complexity, we firstly identified specific concerns about what type of support was needed for users, and then developed and validated a user guidance tool and training environment which addresses those concerns.

This paper is structured as follows: Section 2 gives some background and related work; section 3 describes the research methodology; sections $4-7$ discuss the design and evaluation results of the user survey, OpenSim function network guidance tool and user training environment. Section 8 concludes.

\section{BACKGROUND AND RELATEd WORK}

MULEs demonstrate a great educational potential due to their ability to engage learners in the exploration, construction and manipulation of virtual objects, structures and metaphorical representations of ideas [11]. Various studies of MULE deployments can be found but most of them have assumed incorrectly that MUVEs implicitly facilitate learning opportunities. Since MUVEs are not specifically designed for educational needs, adopters have to consider system and user management to deliver a successful learning experience [12]. Weippl [13] has considered a broad set of factors and use cases for e-Learning system management policies, which was considered in this research, with an appropriate domain mapping.

MUVE based educational projects that have been used as MULE by the authors include: the Laconia Acropolis Virtual Archaeology (LAVA) [14] which allows students to engage in a simulated archaeological excavation and explore a recreation of the site; Wireless Island [15] aids collaborative learning and exploration of wireless traffic through interactive multimedia and simulations; Network Archipelago facilitates learning about Internet routing through study and practice [9]; Second Life and OpenSim were used as the programming platforms for coursework in Human Computer Interaction student projects [16]; the St Andrews Cathedral reconstruction from 1318 [17] is an example of how virtual worlds can uniquely augment and enhance cultural heritage education in a variety of contexts. Research on integrating MUVE with other parts of an institutional e-Learning infrastructure was conducted in [12]. The need for user guidance on the management of MUVE which are to be used as platforms for MULE is a contribution towards making virtual world technology accessible to educators as part of an institution's blended learning facilities.

Mayer's work [18] comes from a cognitive psychology perspective. It is concerned with how the "seductive details" of multimedia learning materials can have a negative impact on learning outcomes. Although he does not appear to have looked at MUVEs per se this is certainly in alignment with our own observations and those of many other virtual worlds educationalists who are familiar with students in a poorly configured MULE ignoring the learning tasks in favour of other activities. Our work seeks to assist educators in configuring and managing MULEs to avoid the problem of "seductive details" such as inappropriate flying or vandalising other learners work.

De Freitas proposed a 4 dimensional framework for designing and evaluating effective learning experience in a MULE: Learner Specifics (e.g. roles, competencies), Representation (e.g. interactivity, immersion), Pedagogy (e.g. cognitive, situated), and Context (e.g. environment, supporting resources)[19, 20]. Our work focuses on supporting educators in creating the right Context in terms of environment and resources.

Lim et al. present a 7 level student engagement taxonomy for MULEs [21]. This consists of: Literary Thinking, Critical Engagement, Self-Regulated Interest, Structuredependent engagement, Frustrated Engagement, Unsystematic engagement, Disengagement. Our work seeks to avoid the lower three types of poor engagement by giving educators guidance on how to create a MULE with a structure which supports the higher levels of engagement.

A taxonomy of MULE educational usages is developed in [22]. It includes: Problem Based Learning, Enquiry Based Learning, Game Based Learning, Role Playing, Virtual Quests, Collaborative Simulations (learn by simulation), Collaborative Construction (building activities), Design Courses (Game, Fashion, Architectural), Language Teaching and Learning, Virtual Laboratories and Virtual Fieldwork. The paper clearly shows that MUVEs, unlike VLEs (Virtual Learning Environments), are not designed for educational use per se, hence our distinction between a MUVE and a MULE, and the need for guidance on how to configure a MUVE as a MULE.

Major policy aspects for MULE management, such as user self-regulation [23] and environment management, were identified in [24]. This informed a policy framework on MUVE functions along with a taxonomy of user interactions. Avatar activities are the main form of user interaction within a MUVE. Twenty-one unique avatar activities were identified in OpenSim These include: content creation \& manipulation, terraforming, content and land management, mobility, presence, appearance, text chat, voice audio and gestures. The taxonomy was used in the development of a policy framework of MUVE functions [20]. 


\section{Research Objectives and Methodology}

The research was organised around two main objectives:

OB1 - To identify specific educator support needs for managing a MULE.

OB2 - To develop practical support materials for educators involved in configuring and managing an OpenSim based MULE.

The first objective was addressed by conducting a survey of postgraduates who were involved in tutoring and demonstrating using a variety of learning resources and environments, including MULEs.

The second objective was met by the development of two resources: a visualisation tool which helps users to understand MUVE functions and their inter-relationships so they can choose the correct configuration options for their educational purposes, and an "in-world" training environment located within a MUVE ${ }^{1}$.

\section{$4 \quad$ Survey Design and Findings}

The survey conducted to achieve the first objective drew upon the participants at a PhD conference which had over $100 \mathrm{PhD}$ students from 13 Universities. The PhD students were engaged in teaching as demonstrators and tutors at the grass-roots level. They were familiar with laboratory experiments, simulations and assessments in a teaching context and were positive towards adopting new technologies, so were particularly suitable for this study.

The questionnaire was designed in accordance with previous findings about user self-regulation and environment management aspects [23]. For accuracy, we tried to minimise the skill and knowledge variance within the sample. The PhD student conference provided an excellent opportunity to educate the audience through a poster and publications presentation portraying the objectives, models and findings of our research.

The study had five questions and an open-ended interview. All data items were collected anonymously; the university affiliation was collected to evaluate the data distribution, which is shown in Fig. 2.

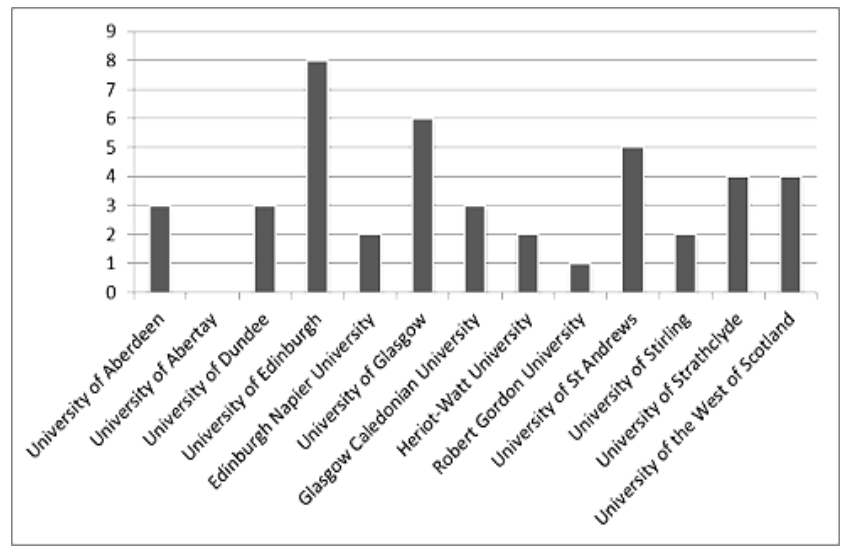

Fig 2: Participant distribution

Questions were designed with a 5-point Likert scale as: Strongly Agree (5) Agree (4), Neither Agree Nor Disagree (3), Disagree (2), Strongly Disagree (1).

As shown in Table 1, the majority of the responses were in favour of the statements resulting in an average $\sim 4$ (Agree) for all questions. ${ }^{2}$ Moreover, questions Q3 and Q5 show Strongly Agree (5) as the most common answer, reinforcing our observations. Q1 was used as an instrument to examine the participants' overall opinion of MUVE facilitated learning. The question was helpful to investigate the participants' perception towards using MUVE for educational activities. As the descriptive statistics indicate, on average, the participants were of the opinion that they agreed $(\mu=3.91)$ with the unique benefits of using MUVE for learning.

Q2, Q3 and Q4 were used to assess attitudes towards Policy Based Management. Pre analysis found that Q2 and Q3 are strongly correlated ${ }^{3}$ indicating that both questions measure the same variable - the effect of the parameters of policy management. We further analysed the participant responses for Q2, Q3 and Q4 and obtained a reliability measure ${ }^{4}$ showing a strong internal consistency. Therefore, combined responses are accurate for the policy-based management variable.

A sample size test was done for fitness using linear regression analysis ${ }^{5}$ which showed that our sample of 43 was valid.

TABLE 1

QUESTIONNAIRE ITEMS AND DESCRIPTIVE STATISTICS OF THE RESPONSES

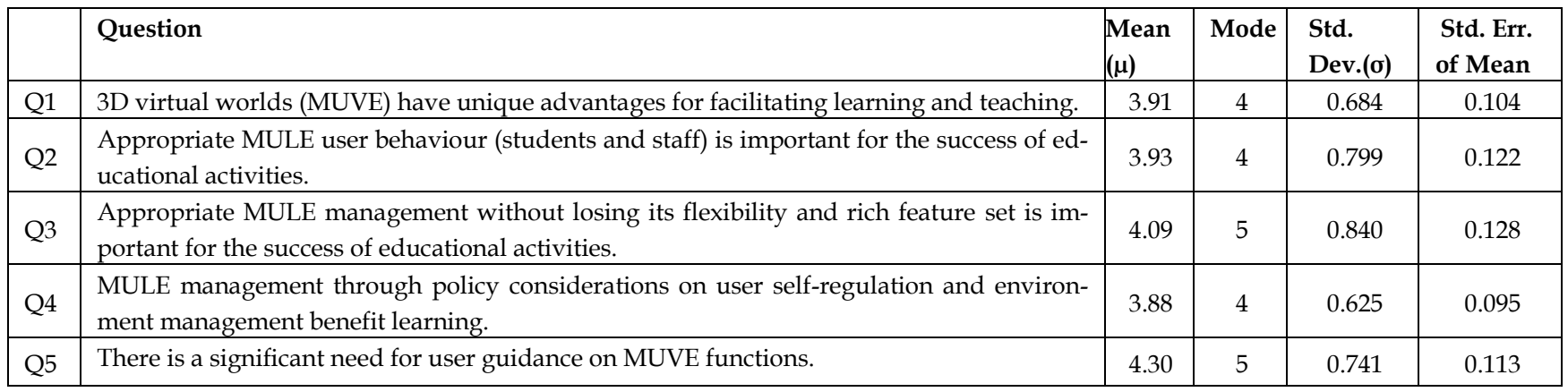

${ }^{1}$ A pre-study [27] showed that custom built in-world training environment was more effective than conventional online training and documentation.

2 Mean values are normally distributed $[X \sim \mathrm{N}(4.022,0.1752)]$, satisfying Kolmogorov-Smirnov (K-S) test with 0.759 significance (using PASW, 18.0).

${ }^{3}$ Spearman's rho $=0.826$ with $\mathrm{p}<0.001$
${ }^{4}$ For the variable Policy Based Management, the Cronbach alpha $=.84$ $(>.80)$. 
This indicated guidance is determined by the decision to follow policy-based management for learning activities in a MULE (Q5). As the model fit test shows, the regression model significantly explains the necessity of policy guidance from the decision to follow policy-based management $(\mathrm{p}<0.001)$.

We conclude that, in order to perform policy-based MULE management, we have to provide the appropriate user guidance on MUVE configuration. This supports our research direction of developing a training environment and tool as a means of providing effective user support.

\subsection{Interview Findings}

Participants were asked to express their opinion, as a qualitative measure, on having user guidance for MUVE functions. We identified three major areas of interest:

- The majority recommended that guidance should be multi-faceted, including students, lecturers and administrative staff. Accordingly, the function network shows the OpenSim function behaviour irrespective of user type. Each user type can be given appropriate permissions based on policies and the nature of a MULE.

- Users had the view that the guidance should be a continuous process until the users are fully competent. Their rationale was that OpenSim is still evolving so a mechanism should be in place for updating the guidance as needed. The training environment developed as part of OB2 accordingly supports this.

- Some were concerned about the relative position of a MULE within the existing learning environment infrastructure, i.e. e-Learning and traditional learning practices. We explained that our models are based on a generic blended learning infrastructure with 3D support, with further discussion available in [12].

A few participants shared their experiences on using a MUVE and the problems they faced. One participant said: "...I was making some ancient Egyptian sculptures on the sandbox given to me; when I was away someone had raised the land and buried my stuff..." This could have been easily avoided, had the appropriate content management and land setting policies been used. In summary, participants' responses validated the point of this research.

\section{The Guidance Tool}

To pursue OB2, graph topology visualization was used as the basis for a guidance tool as suitably structured graphs can enable rapid uptake of abstract information [25]. The open source network visualization tool Gephi [26] was used.

\footnotetext{
${ }^{5}$ As defined by Cohen in [28] and elaborated by Field [29], for the test statistics of anticipated medium-large effect $(F 2=0.21)$, number of predictors $(n=1)$, Probability level of Significance $(\alpha=0.05)$ with the desired statistical Power level of $(1-\beta=0.8)$, the minimum required sample size was 39. Therefore, our sample size $\mathrm{N}=43$ (>39) was appropriate. PASW (18.0) linear regression analysis model summary and the model fit (ANOVA: $\mathrm{F}=89.703, \mathrm{p}<0.001$ ) with $\mathrm{R} 2=0.686$, indicates that about $68.6 \%$ of the variation in the necessity of policy guidance is determined by the decision to
}
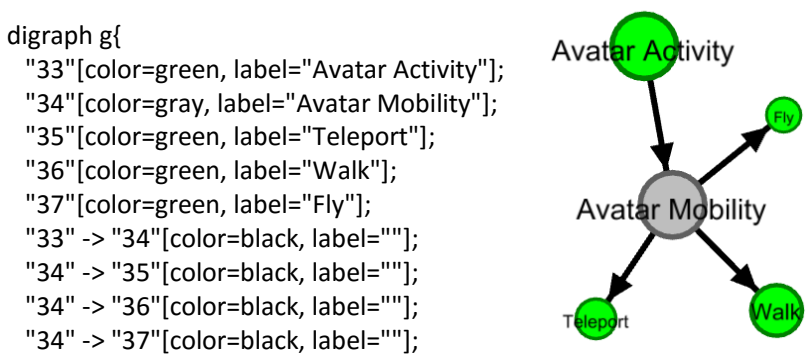

Fig 3: An example script (DOT) and the Gephi output

Using the graph description language DOT [26], networks of function interrelations were generated; a simplified network structure and the code to generate it is shown in Fig. 3.

A statistical analysis was performed to test the network for the accuracy of its structural mapping and its perceived functional significance. Finally, an evaluation was performed using a teaching activity.

\subsection{Analysis of the Function Network}

The full OpenSim function network is shown in Fig.4 to illustrate the potential complexity that educators are faced with when configuring a learning environment.

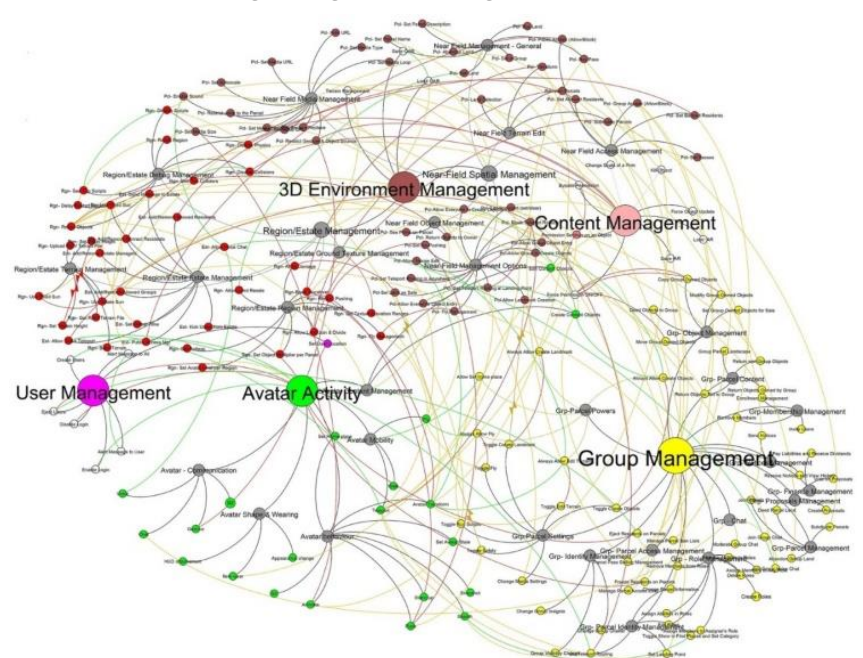

Figure 4: The entire OpenSim Function Network. Core areas for user guidance are: User Management, Avatar Activity, Group Management, Content Management and 3D Environment Management.

Colours are used to distinguish different function categories. Avatar activity functions (green), Group functions (yellow), Content management functions (pink), Land management functions (brown - for near field and red for region level functions) and User management functions (magenta). To depict function interrelationships four colours were used for edges: green for supportive function,

follow policy based management for learning activities in MULE. The ANOVA model fit test shows that the regression model significantly explains the necessity of Policy Guidance from the decision to follow Policy Based Management $(\mathrm{p}<0.001)$. The variable relationship with predictor parameters of the model, i.e., the model path coefficient $(\beta)$, is .828 , which is significant $(\mathrm{p}<0.001)$. 
red for overriding function, amber for operational (toggle) relationship and black for structural links.

To check the accuracy of the function network Eigenvector Centrality (EVC) [30] was used. This also allows lecturers to more readily select candidate functions for policy considerations. EVC is defined as the principal eigenvector of the adjacency matrix defining the network. EVC has been successfully used for similar purposes in previous studies [31]. The EVC metric has two important properties: i) it captures the fact that a node (OpenSim function) that influences many other nodes is influential (has a higher value); ii) it considers a node that affects many highly influential nodes as more influential than a node which affects the same number of weakly influential nodes [31].

TABLE 2

A SAMPLE OF EVC RANKS AND CORRESPONDING PLOS VALUES

\begin{tabular}{|c|l|c|c|}
\hline $\begin{array}{c}\text { EV } \\
\text { Rank }\end{array}$ & \multicolumn{1}{|c|}{ Function } & EVC & PLoS \\
\hline 1 & Content Management & 1.000 & Very High (5) \\
\hline 2 & Teleport & 0.844 & Very High (5) \\
\hline 3 & Avatar Activity & 0.768 & Very High (5) \\
\hline 4 & Avatar Terraform & 0.695 & Very High (5) \\
\hline 5 & Create Content Objects & 0.666 & Very High (5) \\
\hline 6 & Object Permission Settings an & 0.619 & Very High (5) \\
\hline 7 & Avatar Fly & 0.496 & High (4) \\
\hline 8 & Edit Content Objects & 0.451 & Very High (5) \\
\hline 9 & Allow Create Objects & 0.443 & Very High (5) \\
\hline 15 & Manage parcel access list & 0.370 & Very High (5) \\
\hline 18 & Near field spatial management & 0.331 & Very High (5) \\
\hline 19 & Region Estate Management & 0.330 & Very High (5) \\
\hline 34 & Bypass Permissions & 0.289 & High (4) \\
\hline 37 & Group Management & 0.286 & High (4) \\
\hline 38 & Force permission ON/OFF & 0.285 & High (4) \\
\hline 87 & Allow Script Run & 0.209 & Moderate (3) \\
\hline 164 & Alert massages to users & 0.031 & Low (2) \\
\hline 170 & Set Parcel Name & 0.027 & Low (2) \\
\hline 180 & Set Music URL & 0.024 & Low (2) \\
\hline 205 & Group visibility change & 0.003 & Very Low (1) \\
\hline
\end{tabular}

Table 2 shows the relative EV rankings of the OpenSim functions and their Perceived Level of Significance (PLoS), which was obtained as a subjective measure (blind input) from a group of expert 3D-MUVE researchers. The ordinal measures of PLoS were encoded as: Very High $=5$, High $=4$, Moderate $=3$, Low $=2$ and Very Low $=1$. EV follows the approach that all nodes influence their neighbours, without necessarily being confined to the shortest path of node connectivity [32]. This is an appropriate measure as the network has multi-path interlinks (see Fig. 4). To check that there is a significant difference in the distribution of corresponding EVC values across the PLoS categories a Kruskal-Wallis test was used. The result indicated that high EVC values are more likely to be a member of the high importance PLoS population than the low importance population. This confirms the accuracy of EVC values for representing the relative importance of MUVE functions.

\subsection{Tool Use in Teaching - A Case Study}

To evaluate this tool we used one of the educational MUVE projects, Virtual Humanitarian Disaster training
(VHD) [33], as part of a Management degree course module on Non-Governmental Organisations. The VHD project provided a blended MULE with Moodle[34], Sloodle [35] and OpenSim for seamless identity mapping between student accounts and their avatars and consistent linking of learning activities in e-Learning and OpenSim environments (Fig.5 shows the environment and a learning activity). The module has a number of learning objectives associating complex scenarios of teaching and learning support for disaster management, disaster relief provision, decision making and conflict management. For this evaluation VHD teaching and research staff were given the function network diagram with Gephi interface to aid VHD learning environment management. The usual approach involved guessing when a management option is required to be implemented in OpenSim. They were asked to use our tool instead and provide feedback.

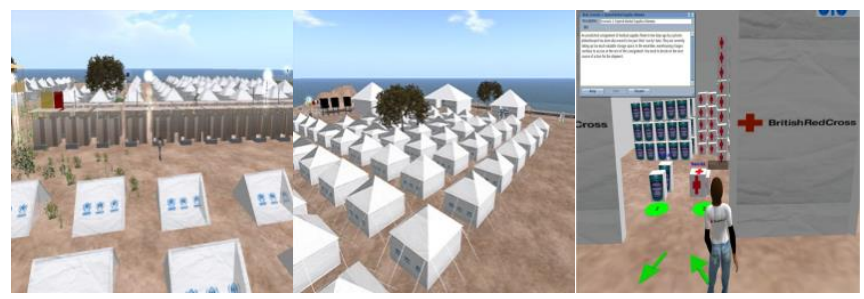

Figure 5: VHD environment and a learning activity in S1

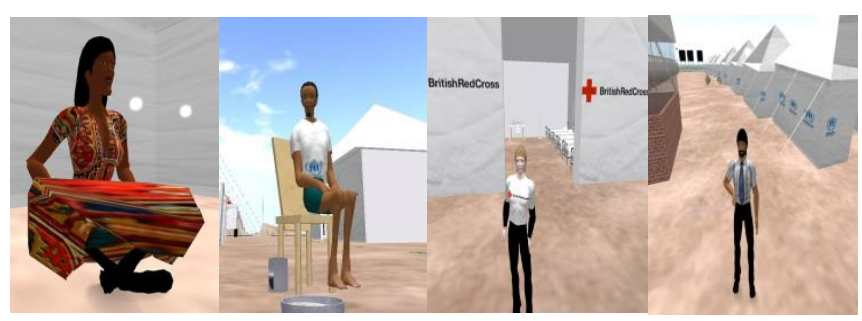

Fig. 6: Student avatars participate in role-plays in S2 (from left: refugee female, refugee male, British Red Cross Aid Worker and Refugee Camp Officer)

Briefly, 3 main learning scenarios were practiced with VHD: i) S1 - basic learning with minimum interactions, ii) S2 - role play and decision making, and iii) S3 - research on disaster management. Fig. 6 shows a student playing different roles in S2, simulating a real world disaster event.

VHD project staff successfully implemented a range of management policies in the VHD MULE to suit each scenario using our tool. For example, in S2 one of the key objectives was to train students about real-world constraints in managing disasters; the ability to personally fly or teleport would obviously be inappropriate. In order to experience and intuitively learn about the practical constraints that one could experience during aid working, students must follow the realistic mobility options such as walking, running or crawling. Similarly, they have to follow dedicated routes such as camp gates, aisles between the camp tents, and avoid barbed wire fences and other barriers. They can also learn about refugee mobility and recommended queuing strategies to be used in case of an emergency. Therefore, two VHD project management policies implemented in S2 were: i) students should refrain from flying during the role-play; ii) students should refrain from teleporting during the role-play. 


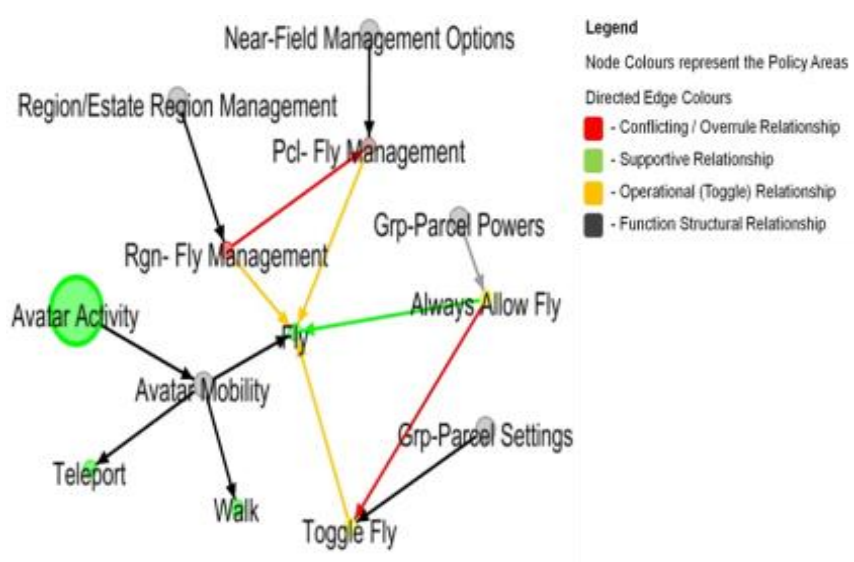

Fig. 7a: Ego Network for Flying

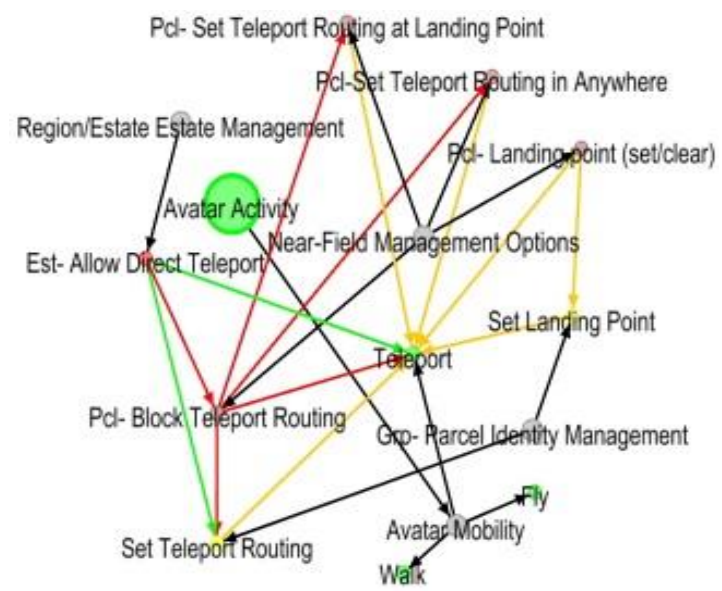

Fig. 7b: Ego network for teleport functions

The complex network visualisation shown in Fig.4 is certainly not intuitive when considered as a whole; however, Gephi supports filtering through ego networks at varying depth levels for a better understanding of localised function complexities and interrelationships. Fig. 7 shows the ego-networks that were used for providing guidance on the implementation of policies on flying and teleporting in S2.

Depending on the various OpenSim user roles and VHD land ownerships such as estate owner, region owner and parcel owner, avatar mobility can be controlled within the owned land. Furthermore, the groups can also affect policy implementations on specific land. More challengingly, depending on the roles practiced, students may be given parcel ownership for roles such as Refugee Camp Officials or Lead Aid Workers on their camp installation parcels; moreover, they can be associated with a group defined for similar role categories.

For example, for controlling avatar flying, the lecturer has to consider 4 functions that control user flying and 6 interactions between those. To control avatar teleport and associated settings, they have to consider 7 functions with 13 interactions. The behaviours of these interactions, as shown in Fig. 7 by the colour coding, can be assessed for their support of the policy requirements. Moreover, the contextual implementation of the policy in OpenSim should be noted. For example, if the VHD learning session encourages flying then the VHD staff have to toggle the appropriate set of functional interactions (green links to be true, red links to be false, and orange links as needed), whereas to restrict flying, they have to toggle their selections for each function the other way around. The guidance tool was used to understand these options by the academics involved in running the VHD environment.

The challenge of managing learning activities in MULE by memorising all interrelated function settings is overwhelming. In the worst case, with $m$ policy considerations in the VHD project learning scenario, each associating $n$ number of MUVE functions, the lecturer or the module coordinator has to consider $m n(n-1)$ number of functional interactions. The implementation of the policies that have been examined within the VHD project would have been very challenging and unproductive without the guidance support provided as the complexity of the arrangement shows polynomial time characteristics. The observations and the feedback received from the VHD project staff were highly positive about the guidance tool for implementing policy decisions which in turn helped them achieve constructive alignment [36] between Learning Outcomes, Teaching and Assessment.

\section{The Training EnVIRONMENT}

As part of achieving OB2 a training environment was designed which featured the visualisation tool in context and allowed for practicing configuration skills in sandboxes. The need for taking the weight of the MULE within a blended learning framework into account was considered. For example, if the OpenSim component of a course has a low weight then asking students to spend a substantial amount of time learning advanced functions may be unnecessary.

Considering the variations in these possible needs two similar regions were developed. The first region, named Introduction Island (Intro-Island), is designed for all users looking for basic training needs. This is similar in concept to Second Life's Help Island. The other region, named Management Island (Mgt-Island), contains training material for advanced functions, including those that are not available in Second Life. Fig. 8 shows the design and the implementation of Intro-Island.

To cover the OpenSim MUVE main function categories [37] a set of training centres were created. Other support areas include (see Fig. 9): Information Centre - for basic information about islands; an Open Forum with Q\&A that shows smart tips and hot keys for managing OpenSim through a client viewer; the Cinema for streaming media displays; Discussion Rooms for small group training sessions; a Sandbox for users to practice their learnt skills. Figure 10 shows examples of tips and guidance notes available in Mgt-Island to help understand content management related problems; Figure 11 shows the graph-visualisation tool being used to explain how teleport permissions interrelate with other functions. 


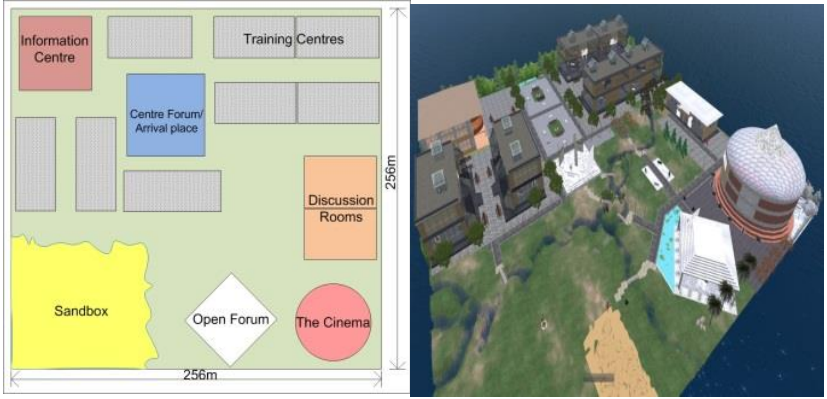

Fig. 8. Introduction Island initial design and implementation
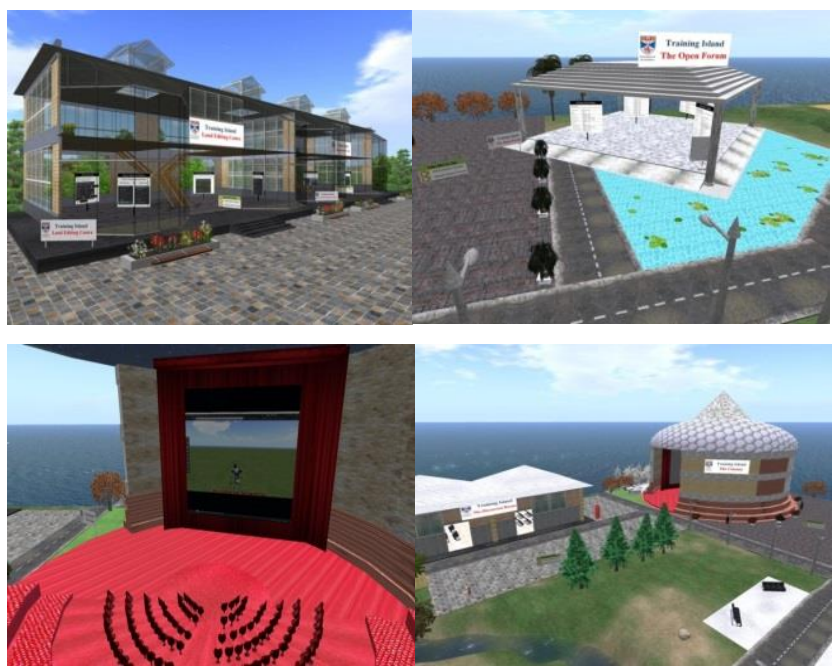

Fig. 9. From top left: A training centre, Open Forum, the Cinema displaying a dedicated video channel for OpenSim training and Discussion rooms for small group training sessions.

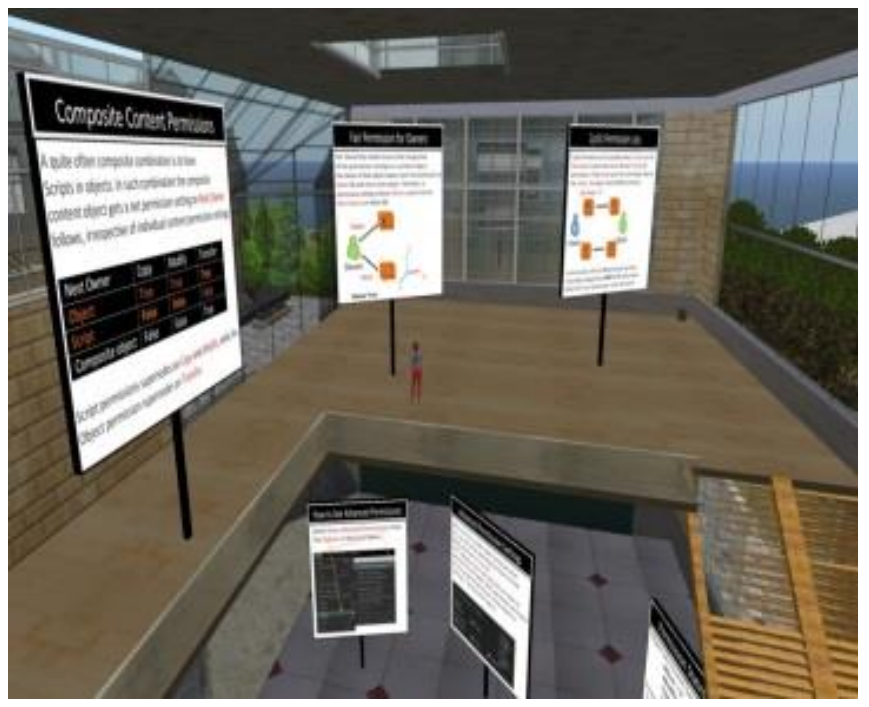

Fig. 10. Area in Mgt-Island showing guidance notes on content management related problems.

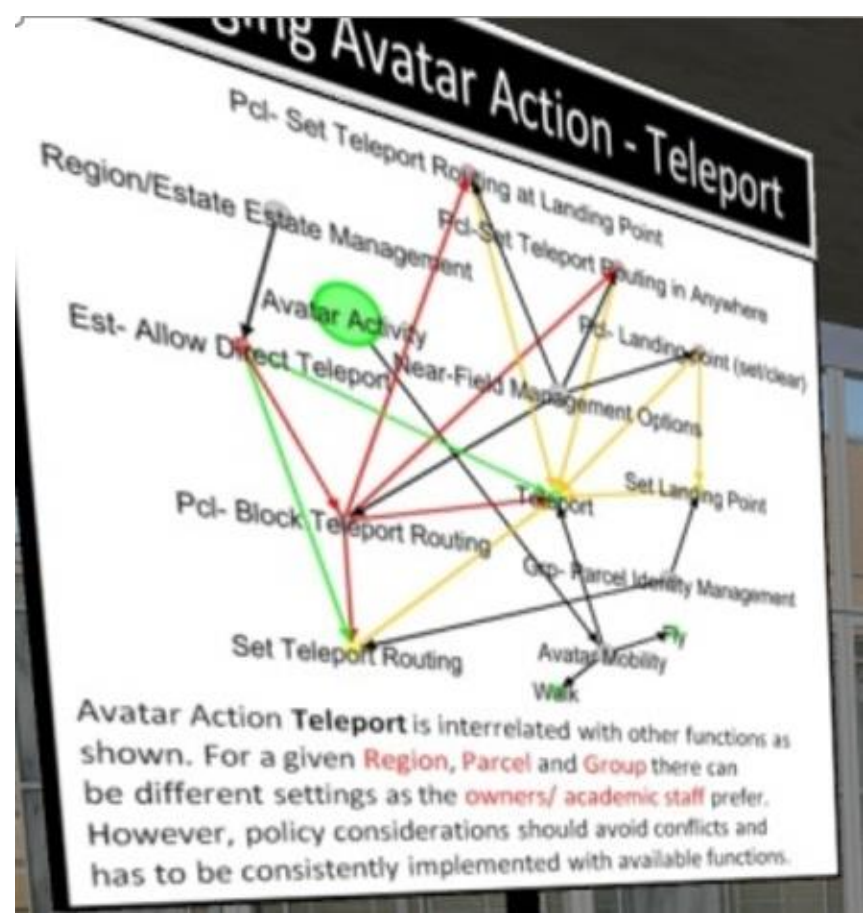

Figure 11: Close-up of Mgt-Island training material showing how teleport permissions inter-relate with other functions

\section{Evaluation of the Training Environment}

The experiment population consisted of academic staff, teaching and research fellows, and postgraduate tutors. The selection of these institutional roles was mainly based on the management tasks they typically practice in academic environments. At the same time, in the institutional context there can be instances where people play multiple roles and also may interchange when a need arises. 70 participants were aimed for ( 35 per group) as the target sample size, leaving enough space to eliminate any outliers or inaccurate data, if present ${ }^{6}$. The complete task scenario, presented in Table 3, shows the association of abstract tasks with real world academic course module requirements for an OpenSim MULE configuration. The experiment setup a 1-hour session per participant allowing for a 40-minute training period and a 20-minute task session with feedback. For the experiment sample the starting place was Introduction Island for 20 minutes and then Management Island for another 20 minutes. The control group used Introduction Island for 40 minutes, making the training time equal for the two groups. After 40 minutes both groups were given the task scenario and the participants were teleported to a specially designed test environment, Experiment Island (Fig. 12 left), to perform the tasks for the remaining 20 minutes. Experiment Island includes learner support centres, land boundaries for setting student parcels for group and individual tasks, and content objects for teaching; all these artefacts are appropriately situated for their management once a participant follows the task scenario.
${ }^{6}$ These types of roles were taken as a single participant population without any role-based discretion for the objectives of the experiment. For the sample size requirement it was planned to set the samples to cater for: an anticipated effect size (Cohen's d $=0.75$ [28], desired statistical power level $(1-\beta)=0.8$, and probability level $\alpha=0.05$; for these conditions the minimum sample size required is 30 participants per group (60 for the total). 
TABLE 3

TASK SCENARIO

You coordinate the course module AB30XX while sharing the lecturing with another faculty member. 12 students have enrolled and you are given 2 PG Tutors for the module.

User accounts have already been created by the system administrator. You are given a region named AB30XX-Learning with the ownership of the Estate/Region. The region contains a sandbox, land areas for individual and group activities, and teaching and learning constructs in a default layout.

When you are inside the region AB30XX-Learning, please complete the following sub tasks to prepare the environment for the course module's teaching and learning requirements.

ST1. Decide suitable OpenSim Roles for each user category i.e. Lecturer, PG Tutor, Student

ST2. Each student has to complete an individual project for the module. Assign the students to the marked land areas: you must create suitable land parcels and provide access restriction. How do you enforce the confidentiality of individual student's work within their land parcel? Identify and use a suitable method. Furthermore, the land parcels should not be considered as sandboxes i.e. actions that affect the parcel whilst learning should be discouraged.

ST3. Ensure that all incoming users arrive at the Information Forum but not elsewhere on the island.

ST4. The sandbox area is unrestricted land for user activities; the other areas except for the given parcels must be restricted from alterations. Set appropriate restrictions in these areas.

ST5. As the default setting, voice is disabled in the region. Enable voice in suitable places. (Hint- lecturing would be quite easy with voice, while library areas/document repositories/study rooms etc. might not be suitable with noise).

ST6. Lecture displays (presentations) and video content can be displayed through suitable media streaming URLs. Set the given displays with the URLs below and ensure that students cannot change or visit other URLs.

Lectures URL: www.myUniversity.edu/video/AB30 Media Content URL blogs. myUniversity.edu / AB30

ST7. Students should be in 4 groups of 3 students per each and assigned to the Tutors ( 2 groups per tutor). Create the required groups with suitable roles and invite the users.

ST8. Student groups must be given land access for their group projects. Set the land parcels suitable for group activities with identified group roles.

ST9. A basic set of content objects for student projects (individual and group) has to be given suitable permissions. Set the permissions for these content objects and place those on the parcels for student access. (Hint - group projects may need collaborative content editing among members. You may also want to prevent accidental deletions of this content by ensuring the original objects given to the students remain intact throughout the course duration.)

ST10. Some of the land areas and content objects (marked) have not been set to your ownership with suitable permission settings. Make those objects and land flexible, to facilitate your course module coordination tasks in the future.

To complete please visit the blended learning area of the island and participate in the quiz.

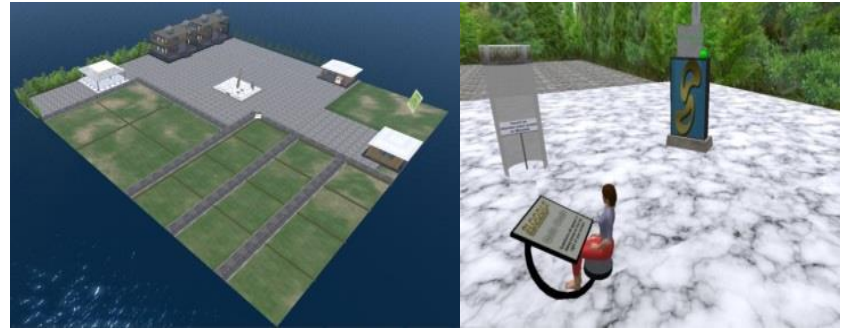

Fig. 12. Experiment Island and an avatar participating in the quiz

A fresh copy of the Training Environment and Experiment Island was used for each participant session. An inworld Multiple Choice Question (MCQ) session was prepared using the Sloodle "Quiz Chair" facility consisting of 10 MCQs. Participants were asked to complete the quiz at the end of the task scenario; see Fig 12(right).

\subsection{Analysis of Results}

This section presents a comparison of the results between the two groups of participants. Intro-Island refers to the group that used Introduction Island only; Mgt-Island refers to the group that used both Introduction and Management Islands. The 10 subtasks have been analysed individually. The figures show averages with error bars based on the standard error.

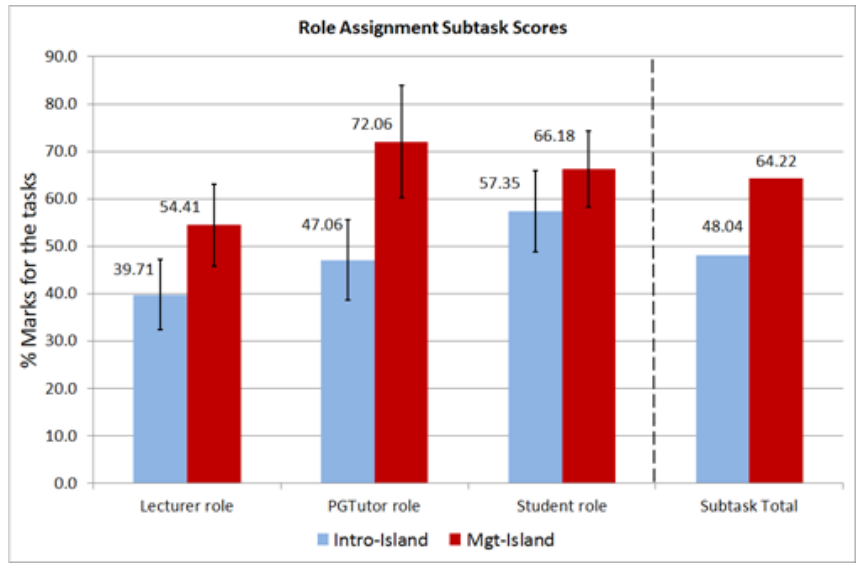

Fig. 13. Average performance scores (\%) for Subtask 1

Subtask 1, role assignment (Fig.13), shows that the MgtIsland group had gained a better understanding of the important task of managing user roles.

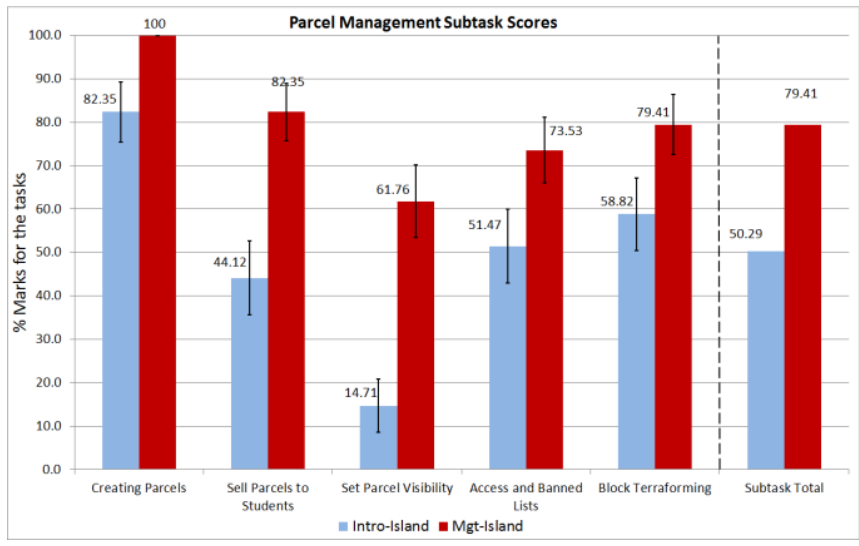

Fig. 14. Average performance scores (\%) for Subtask 2 
Subtask 2, parcel management is shown in Fig. 14. Creating land parcels, a basic activity, is successful for both groups. However, the remaining four activities, particularly parcel selling and setting visibility showed significant differences with Mgt-Island out-performing Intro-Island.

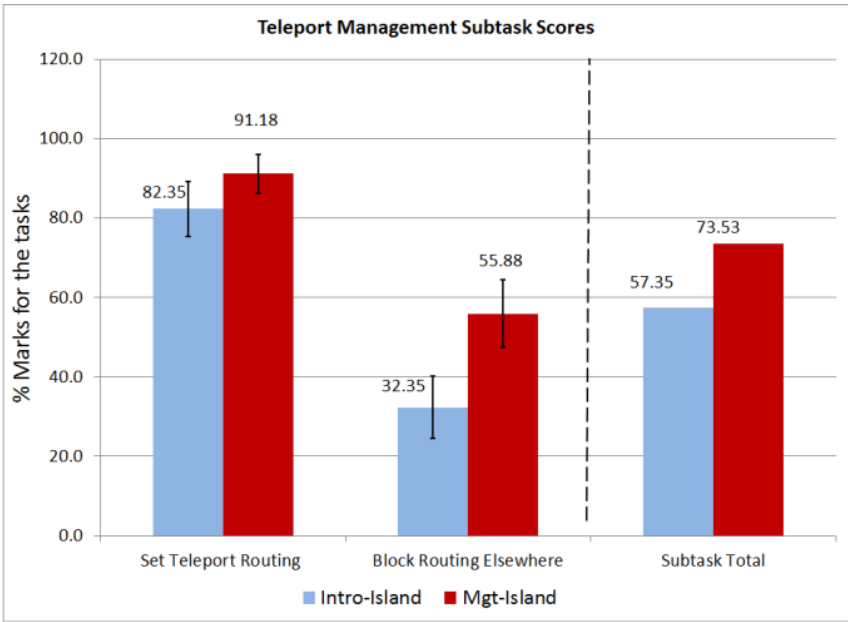

Fig. 15. Average performance scores (\%) for Subtask 3

In Subtask 3, teleport management (Fig. 15), both groups carried out the basic first activity well but in the second task the Mgt-Island group scored significantly better.

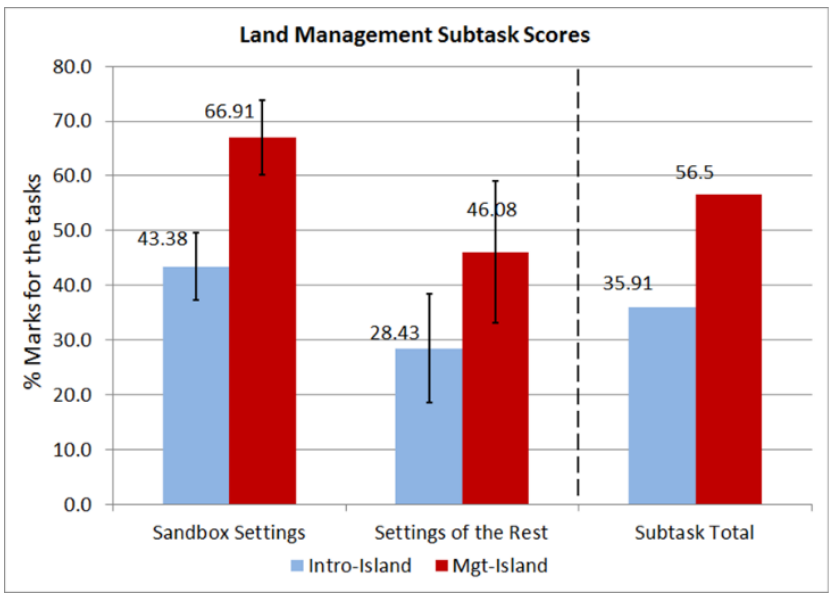

Fig. 16. Average performance scores (\%) for Subtask 4

In Subtask 4 (Fig. 16), complex land configuration, participants were asked to set two different types of land areas: one with settings suitable for sandbox type functionality, and the other for formal educational requirements. Although sandbox settings are comparatively easy, the settings for the other land required a clear understanding of how different settings affect each other and how to avoid conflict situations.

Subtask 5 (Fig. 17) tested for enabling voice communications in appropriate locations. The second activity, identifying suitable locations, required knowledge of different learning activities and MULE learning expectations. The scores suggest that without adequate training for OpenSim management requirements, a mere training on basic UI widgets may not suffice.

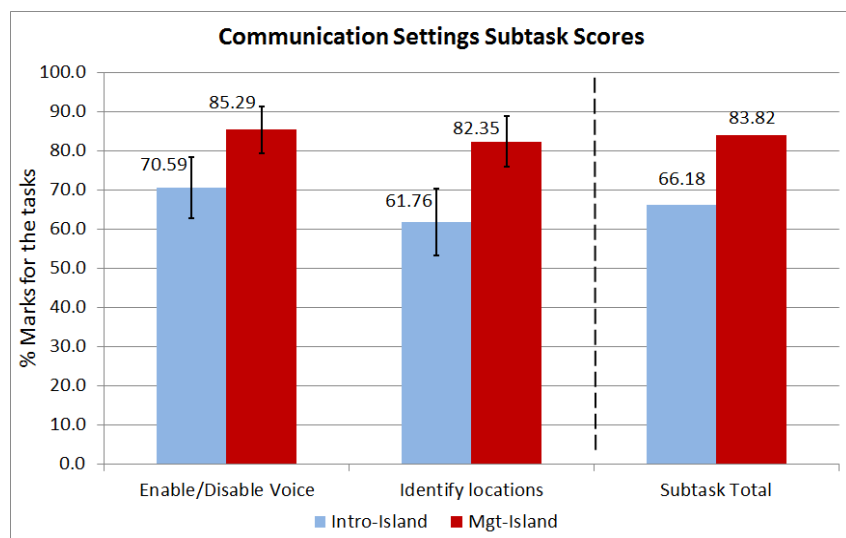

Fig. 17. Average performance scores (\%) for Subtask 5

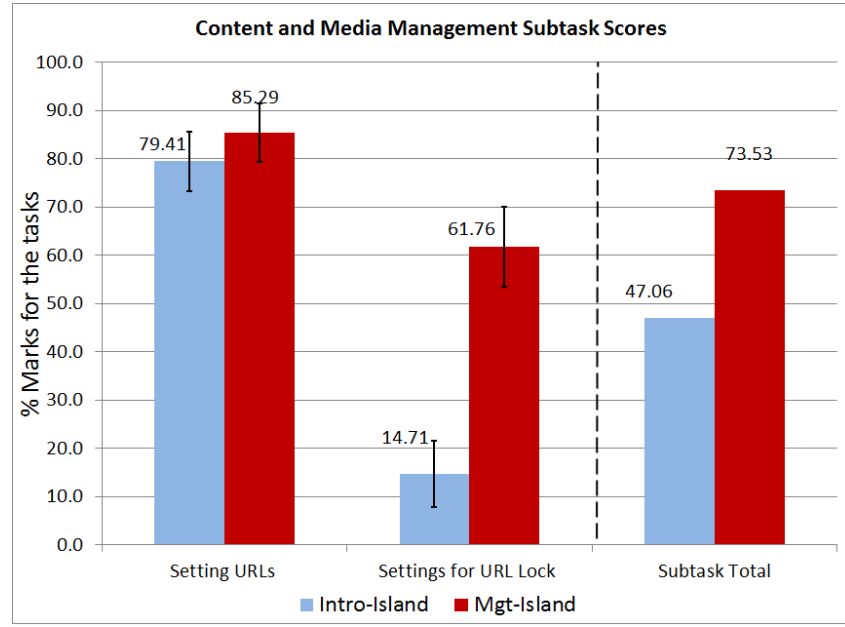

Fig. 18. Average performance scores (\%) for Subtask 6

Subtask 6 (Fig 18) involved importing external content. Embedding URLs, a basic function, was performed well by both groups. However, management of media through URL settings resulted in a much lower score for the IntroIsland group. The URL lock activity is an important content management task that ensures the reliability of learning content. If it is not properly managed, students can easily navigate into arbitrary URIs on the Internet, not only distracting other learners but also bringing harmful or inappropriate content into a learning session. This shows the risk of failing to safeguard a formal educational activity.

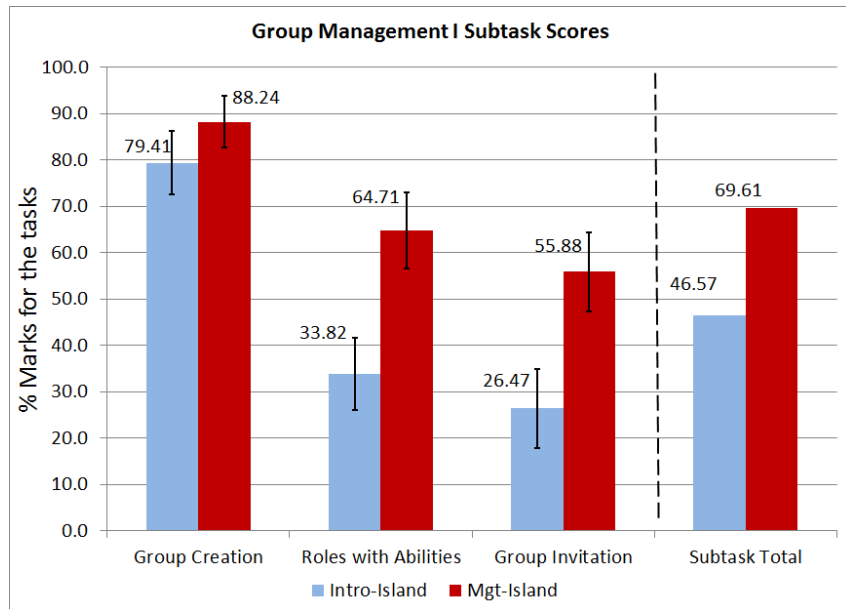

Fig. 19. Average performance scores (\%) for Subtask 7 


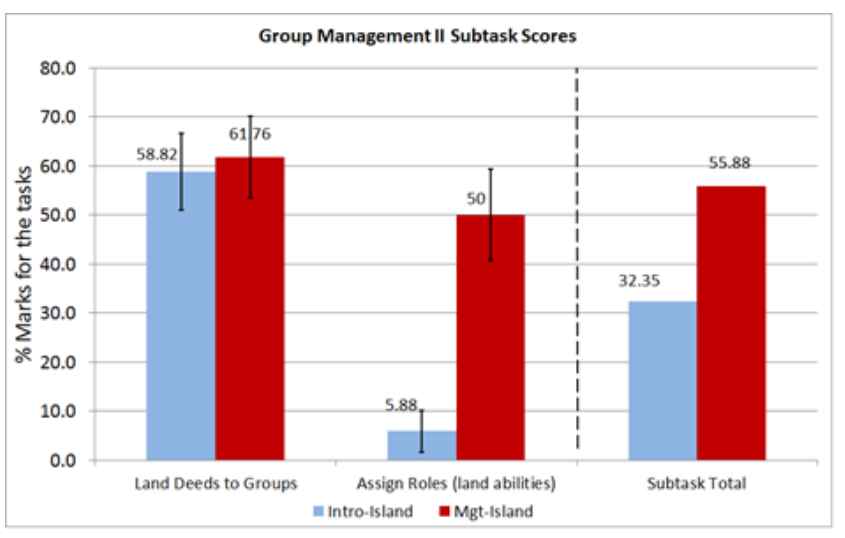

Fig. 20. Average performance scores (\%) for Subtask 8

Subtasks 7 and 8 are concerned with group management. Figs.19 and 20 show that the while both groups did well in basic tasks such as group creation and land deed, the more complex tasks were performed better by the Mgt-Island group.

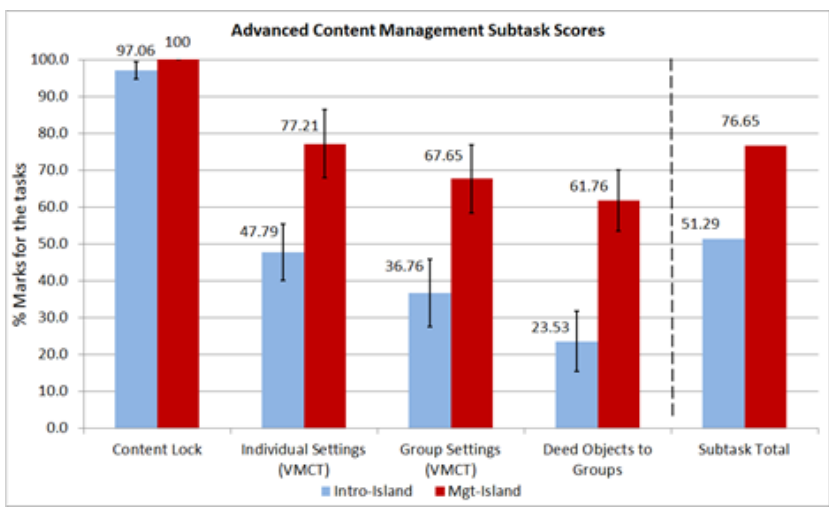

Fig. 21. Average performance scores (\%) for Subtask 9

Subtask 9 is concerned with content management permissions. It starts with the very basic activity of content lock, which was performed quite well by almost all the participants from both groups (Fig. 21). The Intro-Island group scored comparatively less well on the other three activities which required a more thorough understanding of interrelated content settings. VMCT refers to moving content $(\mathrm{V})$, modifying content $(\mathrm{M})$, copying an object $(\mathrm{C})$ and transferring ownership of an object $(\mathrm{T})$.

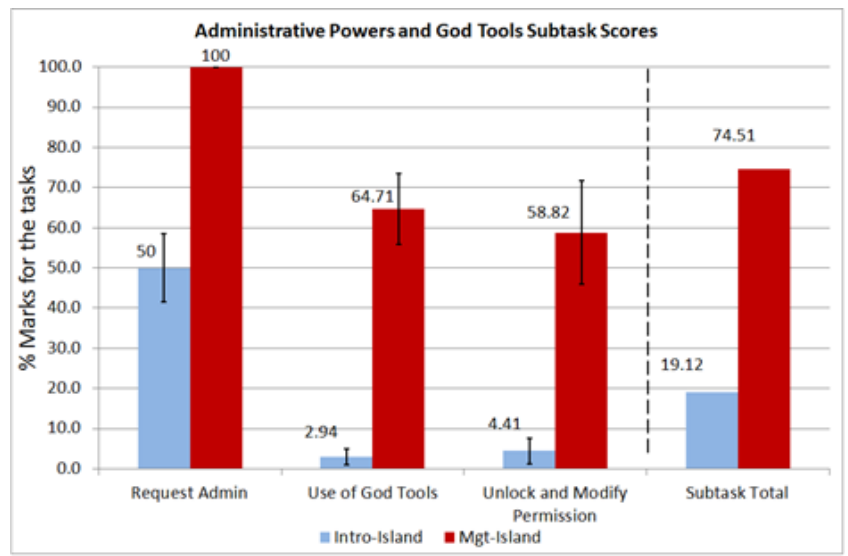

Fig. 22. Average performance scores (\%) for Subtask 10
Subtask 10 included some of the ultimate administration activities that a suitably privileged super user can perform in OpenSim. Although a MULE is set up in advance of student use problems can arise which require academic staff intervention to rectify the state of a learning environment. Fig. 22 shows a marked difference between the MgtIsland and Intro-Island groups in the use of super-user privileges, referred to as "God Tools". Users in Second Life cannot acquire super-user privileges - these are reserved for the company who provide the service - so Second Life training would not help in this context.

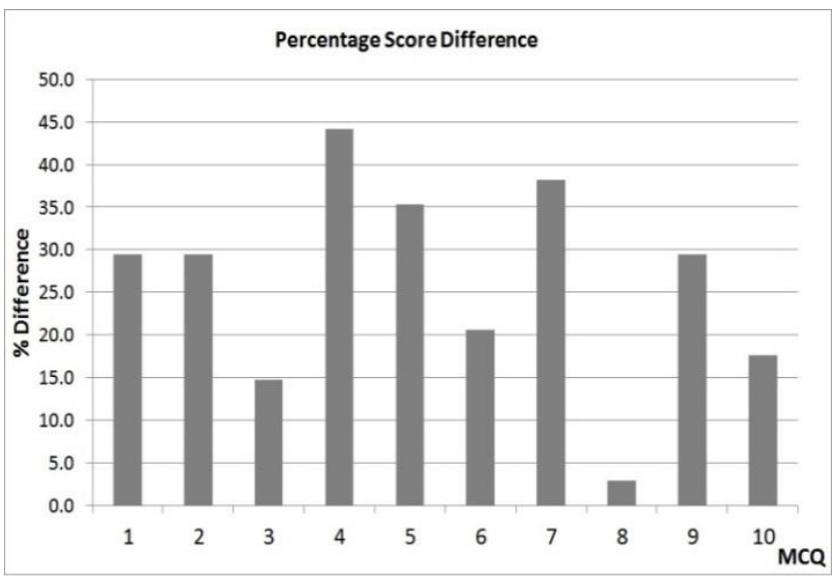

Fig. 23. Percentage score differences per MCQ

Differences between the participants' response scores for the 10 MCQs are shown as percentages (taken as MgtIsland - Intro-Island) in Fig. 23. All the questions reported a positive value indicating that the Mgt-Island sample showed better performance. For questions that examined the participants' knowledge of complex management functions the score differences are very noticeable. An ANOVA test for the mean score difference for the task scenario resulted in $\mathrm{F}=311.886(\mathrm{p}<0.001)$ which suggested that the group score means are significantly different. Mgt-Island mean $=33.206$ and Intro-Island mean $=19.912$ indicated that Mgt-Island trainees showed better performance in managing OpenSim MULE.

\subsection{User Feedback Analysis}

One of the main objectives of this experiment was to compare the usability of the training provided on the two islands. A System Usability Scale (SUS) questionnaire [38] was used at the end of each experiment session. The standard questions and the received average response values for both groups are shown in Table 4. The distribution of the SUS scores is shown in Fig. 24. Other than the frequencies, we can see that the ranges of the SUS score distributions for the two groups are the same suggesting similar results. Moreover, the mean SUS scores are: for Intro-Island group $=73.06$ and Mgt-Island group $=76.18$, which indicate a similar usability experience for the two regions. An ANOVA test indicated that there is no statistically significant difference between the average SUS scores of the two samples $(F=3.80, p>.05)$. This is an interesting finding, which suggests that both islands are more or less equally usable for the purpose of training. We can see that both environments followed the same design architecture, the same ways of presenting content and were situated in the 
same server-client environment of OpenSim; only the training content was different. Therefore, from a usability perspective the islands are likely to be equally usable, which was found to be true statistically as per the analysis. Both islands reported an average score of 74.89 suggesting very good usability.

TABLE 4

USABILITY EVALUATION

\begin{tabular}{|l|c|c|}
\hline \multirow{2}{*}{ Question } & \multicolumn{2}{|l|}{$\begin{array}{l}\text { Average Response } \\
\text { Value }\end{array}$} \\
\cline { 2 - 3 } & $\begin{array}{l}\text { Intro-Is- } \\
\text { land }\end{array}$ & $\begin{array}{l}\text { Mgt-Is- } \\
\text { land }\end{array}$ \\
\hline $\begin{array}{l}\text { I think I would like to use this system fre- } \\
\text { quently }\end{array}$ & 3.94 & 3.59 \\
\hline I found the system unnecessarily complex & 1.85 & 1.94 \\
\hline I thought the system was easy to use & 3.86 & 4.09 \\
\hline $\begin{array}{l}\text { I think that I would need the support of a } \\
\text { technical person to be able to use this sys- } \\
\text { tem }\end{array}$ & 2.09 & 1.94 \\
\hline $\begin{array}{l}\text { I found the various functions in this sys- } \\
\text { tem were well integrated }\end{array}$ & 3.82 & 3.76 \\
\hline $\begin{array}{l}\text { I thought there was too much incon- } \\
\text { sistency in this system }\end{array}$ & 2.15 & 1.82 \\
\hline $\begin{array}{l}\text { I would imagine that most people would } \\
\text { learn to use this system very quickly }\end{array}$ & 3.79 & 4.26 \\
\hline $\begin{array}{l}\text { I found the system very cumbersome to } \\
\text { use }\end{array}$ & 1.82 & 1.80 \\
\hline I felt very confident using the system & 3.88 & 4.01 \\
\hline $\begin{array}{l}\text { I needed to learn a lot of things before I } \\
\text { could get going with this system }\end{array}$ & 1.94 & 1.70 \\
\hline
\end{tabular}

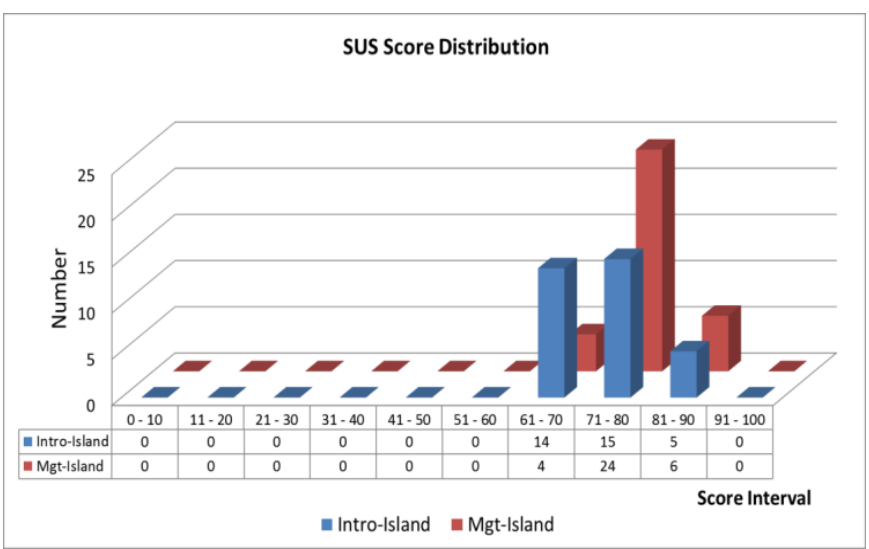

Fig. 24. The distribution of SUS scores

Perceived educational value was measured using a variant of the SUS questionnaire. The questions and the respective average scores for both groups are shown in Table 5. Both groups indicated that they felt they had learnt something new in general. However, the scores for specific topics showed a clear difference between the groups. In particular, the 6th, 8 th and 9th questions asked about the educational value for completing the given tasks; the Intro-Group on average disagreed with these statements reflecting the lack of support received. In contrast, the Mgt-Island group strongly agreed with those statements indicating that the training they had received from Management Island was sufficient to perform OpenSim management tasks. Overall, the Mgt-Island group showed an average perceived educational value of 86.47 and Intro-Island participants showed a value of 68.89 . This high difference is also visible in the score distribution shown in Fig. 25.
TABLE 5

Perceived Educational Value

\begin{tabular}{|l|c|c|}
\hline Question & \multicolumn{2}{|l|}{$\begin{array}{l}\text { Average Response } \\
\text { Value }\end{array}$} \\
\cline { 2 - 3 } & $\begin{array}{l}\text { Intro-Is- } \\
\text { land }\end{array}$ & $\begin{array}{l}\text { Mgt-Is- } \\
\text { land }\end{array}$ \\
\hline $\begin{array}{l}\text { I felt I have learnt something by using this } \\
\text { system }\end{array}$ & 4.62 & 4.41 \\
\hline $\begin{array}{l}\text { The content on the Training Islands pro- } \\
\text { vides believable information }\end{array}$ & 4.35 & 4.32 \\
\hline $\begin{array}{l}\text { I found it easy to find out information on } \\
\text { various complex 3D MUVE functions and } \\
\text { settings }\end{array}$ & 3.35 & 4.59 \\
\hline $\begin{array}{l}\text { The quality of the material presented was } \\
\text { consistent }\end{array}$ & 4.03 & 4.20 \\
\hline $\begin{array}{l}\text { Interactive settings and practicing the } \\
\text { training tasks in-world allowed me to im- } \\
\text { prove my skills on using virtual worlds }\end{array}$ & 4.06 & 4.55 \\
\hline $\begin{array}{l}\text { I feel that using this system helps to de- } \\
\text { velop my understanding of how to manage } \\
\text { 3D Multi User Learning Environments }\end{array}$ & 2.56 & 3.91 \\
\hline $\begin{array}{l}\text { I found the system educationally stimulat- } \\
\text { ing }\end{array}$ & 3.74 & 4.29 \\
\hline $\begin{array}{l}\text { I was able to practice different manage- } \\
\text { ment settings easily after using the system }\end{array}$ & 2.29 & 4.02 \\
\hline $\begin{array}{l}\text { The knowledge provided by the system al- } \\
\text { lowed me to practice various tasks on man- } \\
\text { aging the virtual environment }\end{array}$ & 1.82 & 4.47 \\
\hline $\begin{array}{l}\text { The educational content was intuitive and } \\
\text { easy to understand }\end{array}$ & 3.61 & 4.44 \\
\hline
\end{tabular}

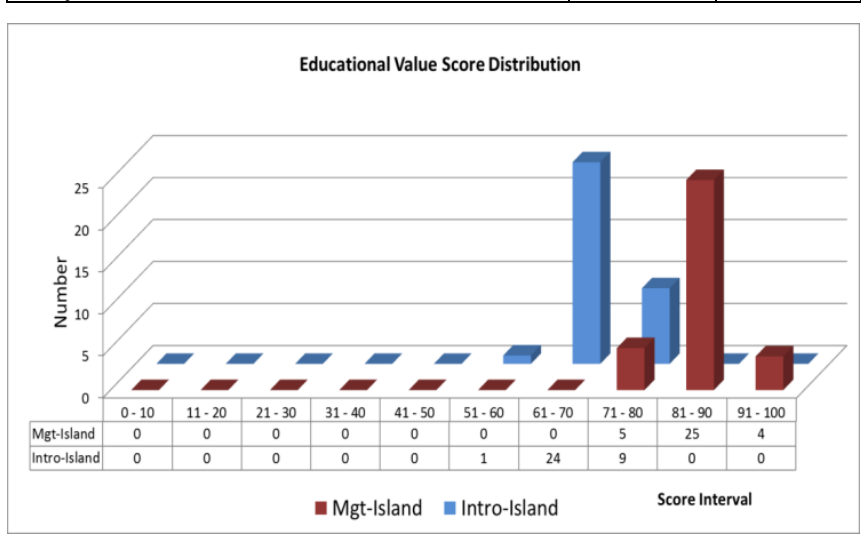

Fig. 25. The distribution of perceived educational value scores

We can see the range of Mgt-Island educational value distribution is shifted two intervals towards the full-score compared to the control sample. ANOVA test indicates that there is a statistically significant mean difference of perceived educational value between the two groups $(\mathrm{F}=265.76, \mathrm{p}<.001)$; a higher perceived educational value was reported for Management Island indicating its unique contributions for training users for managing OpenSim MULE.

\subsection{Open Feedback}

At the end of each session a concluding discussion was opened up. A few of the participants said that they had no questions and finished the study without having this discussion. In general, the participants found the entire session was interesting and enjoyable. They had learned new skills and trained themselves in using OpenSim as a MULE. The participants from the Mgt-Island group said they could perform scenario tasks well at the end, despite 
having known nothing about the management functions beforehand. This was positive and encouraging feedback that stressed the value of the training environment.

However, the Intro-Island group often noted that the training they had was not adequate, particularly in reference to the task scenario. They said that Introduction Island should be extended by including training content for advanced tasks. This was in fact, a further support for the research case that specific training on OpenSim functions is important for managing OpenSim MULE. When they were informed that they were the control sample, and that there was another island for management training, they showed a keen interest in using Management Island. They were informed that once the study was completed it would be part of the university virtual world grid and available for download from the open virtual world repository [39].

Some participants initially expressed a preference to have a multi-user session with others. Once the clarification was made that the individual sessions were specially designed for obtaining data as part of a research evaluation they were happy to proceed.

\subsection{Experiment Limitations}

The experiment and its evaluation were affected by the following limitations. Careful measures with rigorous statistical methods and pre-tests were used to minimise the impact of these limitations.

The participants showed differences in the ways they preferred to interact and perform the given tasks, indicating different intrinsic personal skill traits. Certain approaches resulted in efficient completion of tasks while some other methods took longer times. However, this effect was distributed randomly in both groups and had equal effect in both samples; thus the comparison of performance was not affected. Moreover, any user session that was significantly affected by the time limit was not observed; often, it was the case that the participants were not aware of the functions and settings to use. Secondly, the data collection used did not take account of failed attempts at the given tasks. The halfway attempts were not considered for the task scores. However, this was common for both groups therefore did not affect the comparative analysis. The feedback captured through Lickert scale responses had quantified ordinal values, which may not provide an exact value for their response, but rather a range. However, this is a well-known feature in user studies; appropriate statistical tests were used and the data found suitable for the analysis.

\subsection{Implications for MULE Management}

Configuring a MUVE such as OpenSim as a successful MULE requires a more detailed knowledge of MUVE functionalities and settings and the interrelationships between them than can be acquired from typical MUVE general introductory training environments and programmes e.g. Second Life's Help Island. Interestingly, from our results it would appear that providing a more sophisticated and educationally focused training environment such as that described in 6.1 featuring Mgt-Island does not result in consuming more time or generating poorer usability or perceived educational value scores than confining participants to the much simpler Intro-Island. Future work will investigate the feasibility of combining these two training environments into one.

\section{Conclusions AND Future Work}

The goal of this research was to investigate the type of user support needed for managing OpenSim-based MULEs and to provide tools and training to address those needs. The findings suggested that there is a strong need for systematic, policy-based management of a MULE and for suitable user support for such practice. An OpenSim function network was developed using a graph-theoretic approach. This proved to be highly useful, allowing academic staff to understand particular functions and their interrelationships in order to configure a MULE. The training environments implemented for both basic and advanced MULE management indicated that users have benefited most by learning the more advanced functions supported by Management Island, regardless of the weight given to a MULE in a blended learning framework.

This research used the OpenSim core system and functional models as the basis for the user support tools and facilities developed. To the extent that OpenSim is based on Second Life some of these competencies will also be valid in Second Life, but it is important to note that many of the advanced functions are only available to OpenSim "super-users" and not available to users in Second Life as it is a commercially provided service where the providers retain privileged powers. In the OpenSim case users typically provide their own MUVE service, even when using cloud-based facilities.

OpenSim systems continue to grow and evolve. For example, one aspect not addressed by this research is the OpenSim hypergrid which allows for the interconnection of multiple OpenSim grids belonging to different administrative regimes. This clearly has the possibility of raising new management challenges in the areas of access control, ownership, content management, and security. We believe that there should be further research on how the management practices of MULE from different institutions can cohesively work together while meeting the challenges presented by the hypergrid infrastructure; to that end the user support models and tools developed in this research can be extended as required. Such research will be important for the success of interconnected multi-institutional MULEs in future, and contribute towards a model of a 3D Web for immersive learning. At present comparable versions of immersive environments accessed from a web browser and a conventional standalone virtual world client viewer show that while the web browser version is much easier to access and use, it has far fewer functions and is severely constrained in the size, complexity and interactivity of a virtual world representation [40].

In summary, this work has shown that the right sort of user support can substantially improve the competencies of OpenSim users in managing learning environments thereby making such technologies more amenable to adoption in mainstream educational practice. 


\section{ACKNOWLEDGMENTS}

This research was supported by the Commonwealth Scholarship Programme (UK) and the Scottish Informatics and Computer Science Alliance (SICSA).

The authors thank the reviewers for their helpful feedback.

Corresponding author: Colin Allison,

ca@st-andrews.ac.uk.

\section{REFERENCES}

[1] Linden_Labs. (2003, November 2015). Second Life. Available: www.secondlife.com

[2] The_Open_Simulator_Project. (2008, December 2015). OpenSim. Available: http://opensimulator.org/wiki/Main Page

[3] Firestormviewer.org, "Firestorm. http://www.firestormviewer.org/downloads/," ed, 2016.

[4] L. Labs, "Second Life Viewer. https://secondlife.com/support/downloads/," ed, 2016.

[5] NASA. (2010, Learning Technologies Project FY10 Performance Report Project.

http://www.nasa.gov/pdf/505587main 2010 ESE LT.pdf.

[6] C. Allison, T. Sturgeon, A. Miller, G. I. U. S. Perera, and J. R. N. Nicoll, "Educationally Enhanced Virtual Worlds," presented at the 40th IEEE Frontiers in Education Conference, 2010. FIE '10., Washington, 2010.

[7] C. Allison, A. Miller, K. Getchell, and T. Sturgeon, "Exploratory Learning for Computer Networking in ICWL 2007," Lecture Notes in Computer Science, vol. 4823/2008, pp. 331-342, 2008.

[8] J. P. McCaffery, A. H. D. Miller, and C. Allison, "Extending the Use of Virtual Worlds as an Educational Platform - Network Island: An Advanced Learning Environment for Teaching Internet Routing Algorithms," presented at the 3rd International Conference on Computer Supported Education (CSEDU 2011). Netherlands, 2011.

[9] J. McCaffery, A. Miller, I. Oliver, and C. Allison, "Augmented Learning Roads for Internet Routing," presented at the 2014 IEEE Frontiers in Education Conference, Madrid, 2014.

[10] C. Girvan and T. Savage, "Identifying an appropriate pedagogy for virtual worlds: A Communal Constructivism case study," Computers \& Education, vol. 55, pp. 342-349, 2010.

[11] B. Dalgarno, A. G. Bishop, W. A. and, and D. R. B. Jr., "Effectiveness of a Virtual Laboratory as a preparatory resource for Distance Education chemistry students," Computers \& Education vol. 53, pp. 863-865, 2009.

[12] I. Perera, C. Allison, M. J., and A. Miller, "Towards Effective Blended Learning With 3D MUVE - An Analysis of Use Case Implementations for 3D MUVE Learning," presented at the 3rd Computer Supported Education - CSEDU2011, The Netherlands, 2011.

[13] E. R. Weippl, Security in E-learning, 1 ed. vol. 16: Springer US, 2005

[14] K. Getchell, A. Miller, J. R. Nicoll, R. J. Sweetman, and C. Allison, "Games Methodologies and Immersive Environments for Virtual Fieldwork," IEEE Transactions on Learning Technologies, vol. 3, pp. 281-293, 2010.

[15] T. Sturgeon, C. Allison, and A. Miller, "802.11 Wireless Experiments in a Virtual World," ACM SIGCSE Bulletin, vol. 41, pp. 85-89, 2009.

[16] I. Perera, C. Allison, J. R. Nicoll, T. Sturgeon, and A. Miller, "Managed Learning in 3D Multi User Virtual Environments," International Journal of Digital Society, vol. 1, pp. 323-332, 2010.

[17] S. Kennedy, R. Fawcett, A. Miller, L. Dow, R. Sweetman, A.
Field, et al., "Exploring canons \&amp; cathedrals with Open Virtual Worlds: The recreation of St Andrews Cathedral, St Andrews day, 1318," in Digital Heritage International Congress (DigitalHeritage), 2013, 2013, pp. 273-280.

[18] S. F. Harp and R. E. Mayer, "How seductive details do their damage: A theory of cognitive interest in science learning," Journal of Educational Psychology, vol. 90, pp. 414-434, 1998.

[19] S. de Freitas and M. Oliver, "How can exploratory learning with games and simulations within the curriculum be most effectively evaluated?," Computers \& Education, vol. 46, pp. 249-264, 4// 2006.

[20] S. de-Freitas, G. Rebolledo-Mendez, F. Liarokapis, G. Magoulas, and A. Poulovassilis, "Learning as immersive experiences: Using the four-dimensional framework for designing and evaluating immersive learning experiences in a virtual world," British Journal of Educational Technology, vol. 41, pp. 69-85, 2010.

[21] C. P. Lim, D. Nonis, and J. Hedberg, "Gaming in a 3D multiuser virtual environment: engaging students in Science lessons. ," British Journal of Educational Technology,, vol. 37 pp. 211-231, 2006.

[22] I. Duncan, A. Miller, and S. Jiang, "A taxonomy of virtual worlds usage in education," British Journal of Educational Technology, vol. 43, pp. doi: 10.1111/j.1467-8535.2011.01263.x, 2012.

[23] I. Perera and C. Allison, "Self-Regulated Learning in Virtual Worlds - An Exploratory Study in OpenSim," presented at the Immersive Learning Research Network Conference (iLRN 2015 Prague), Prague, 2015.

[24] I. Perera, C. Allison, and A. Miller, "Effective Policy Based Management of 3D MULE - An Exploratory Study Towards Developing Student Supportive Policy Considerations " presented at the 4th CSEDU, 2012.

[25] I. Herman, G. Melancon, and M. Marshall, "Graph visualization and navigation in information visualization: A survey," IEEE Transactions on Visualization and Computer Graphics, vol. 6, pp. 24-43, 2000.

[26] M. Bastian, S. Heymann, and M. Jacomy, "Gephi: An Open Source Software for Exploring andManipulating Networks," presented at the International AAAI Conference on Weblogs and Social Media, 2009.

[27] I. Perera, C. Allison, and A. Miller, "User Training for 3D Virtual Worlds: An Evaluation of Training Approaches," presented at the 15th International Conference on Computer Modelling and Simulation, UKSim'13, Cambridge, 2013.

[28] J. Cohen, Statistical Power Analysis for the Behavioural Sciences 2ed.: Academic Press, 1988.

[29] A. Field, Discovering Statistics using SPSS, 2 ed. London: SAGE, 2006.

[30] P. Bonacich, "Factoring and weighting approaches to status scores and clique identification," Journal of Mathematical Sociology, vol. 2, pp. 113-120, 1972.

[31] D. Greenwood and I. Sommerville, "Using Network Analysis and Visualization to Analyse Problematic Enterprise Information Systems," International Journal of Knowledge and Systems Science, vol. 2, pp. 54-71, 2011.

[32] S. P. Borgatti, "Centrality and Network Flow," Social Networks, vol. 27, pp. 55-71, 2005.

[33] O. Ajinomoh, L. Dow, A. Miller, A. Gordon-Gibson, and E. Burt, "Managing Humanitarian Emergencies: Teaching and Learning with a Virtual Humanitarian Disaster Tool," in 4th International Conference on Computer Supported Education (CSEDU 2012), Oporto, Portugal, 2012, pp. 55-64.

[34] Moodle_PTY_Ltd. (2015, December). About Moodle. Available: https://docs.moodle.org/30/en/About Moodle 
[35] J. W. Kemp, D. Livingstone, and P. R. Bloomfield, "SLOODLE: Connecting VLE tools with emergent teaching practice in Second Life," British Journal of Educational Technology, vol. 40, pp. 551-555, 2009.

[36] J. B. Biggs, "Enhancing teaching through constructive alignment," Higher Education, vol. 32, pp. 347-364, 1996.

[37] I. Perera, C. Allison, and A. Miller, "Policy Considerations for Managing 3D Multi User Learning Environments - Achieving Usability and Trust for Learning," in 6th ICVL, 2011, pp. 106112.

[38] J. Brooke, "SUS - A quick and dirty usability scale http://www.usabilitynet.org/trump/documents/Suschapt.doc," in Usability Evaluation in Industry, B. T. P. W. Jordan, B. A.

Indika Perera is a senior lecturer, attached to the Department of Computer Science and Engineering at the University of Moratuwa, Sri Lanka. Indika holds a Ph.D. in Computer Science from the University of St Andrews, U.K where he studied as a member of the Open Virtual Worlds research group. The focus of his Ph.D. was managing immersive technologies for education. He has also received a Master's in Business Studies (MBS) from the University of Colombo, a Masters in Computer Science (MSc) from the University of Moratuwa, a Postgraduate Diploma in Business Management from the University of Colombo and a Bachelor of Science of Engineering (B.Sc. Eng. Hons) from the University of Moratuwa. His research interests include areas of software architecture and software engineering; software process and management, technology enhanced learning, user experience design, and immersive technologies. He has been serving as an ICT consultant for several large-scale government and private sector projects in Sri Lanka. He is a Fellow of the Higher Education Academy (UK), member of IET (UK) and member IEEE. He is also a Charted Engineer registered at Engineering Council (UK) and Institute of Engineers, Sri Lanka.
Weerdmeester, \& A. L. McClelland, Ed., ed London: Taylor and Francis, 1996.

[39] OVT_Research_Group. (2015, November). Open_Virtual_Worlds. Available: http://www.openvirtualworlds.org/

[40] H. Bakri, C. Allison, A. Miller, and I. Oliver, "Virtual Worlds and the 3D Web - Time for Convergence?," in Immersive Learning Research Network: Second International Conference, iLRN 2016 Santa Barbara, CA, USA, June 27 - July 1, 2016 Proceedings, C. Allison, L. Morgado, J. Pirker, D. Beck, J. Richter, and C. Gütl, Eds., ed Cham: Springer International Publishing, 2016, pp. 29-42.

Alan Miller is a Lecturer in the School of Computer Science at the University of St Andrews, UK and a member of the Open Virtual Worlds research group. He has been actively involved in learning technologies for over 15 years. His main current research interest is in the development and use of cuttingedge virtual and augmented reality to support publicly accessible digital and culture heritage installations.

Colin Allison is a Reader in the School of Computer Science at the University of St Andrews, UK. He is a board member of the Immersive Learning Research Network (ILRN) and a member of the Open Virtual Worlds research group based in St Andrews. He has been involved with computer supported learning for over 25 years and has published over 150 peerreviewed articles. He is a member of the IEEE and ACM and numerous conference program committees. His research has always involved the development and deployment of systems with real users and evaluating them from usability, usefulness, performance and technology perspectives. His current research interests include immersive learning and the 3D Web. 